con mejoría en la evolución clínica del cuadro infeccioso, al utilizar factores estimulantes de las colonias de granulocitos (granulocyte-colony stimulating factors - G-CSF) ${ }^{11}$ aunados a la antibioticoterapia. En este caso no ha sido necesario el uso de estos factores estimulantes, pues no se han presentado episodios infecciosos graves.

Otras causas de neutropenia en pacientes con infección por VIH están relacionadas con un desbalance en la producción de neutrófilos, con destrucción acelerada de los neutrófilos debido a anticuerpos circulantes, daño al progenitor granulocítico medular, ${ }^{6}$ deficiencias nutricionales como falta de vitamina $B_{12}$, presencia de anticuerpos contra la glicoproteína gp 120 de la cápside viral del VIH,${ }^{10}$ apoptosis acelerada que acorta la sobrevida de los neutrófilos. ${ }^{12}$ En el caso presentado se plantea que el VIH ha producido un daño sobre el progenitor granulocítico, que explicaría la alteración hematológica temprana y que ha persistido aún con la terapia adecuada, pero que no ha producido consecuencias sobre la función de los neutrófilos, pues el paciente no ha presentado complicaciones infecciosas graves.

\section{Referencias}

1. Meynard JL, Guiguet M, Arsac S, Frottier J, Meyohas MC. Frecuency and risk factors of infectious complications in neutropenic patients infected with HIV. AIDS 1997;11:995-998.

2. Hsieh MM, Everhart JE, Byrd-Holt D, Tisdale JF, Rodgers GP. Prevalence of neutropenia in the U.S. population: age, sex, smoking status and ethnic differences. Ann Intern Med 2007;146:486-492.
3. Ibáñez L, Vidal X, Ballarín E, Laporte JR. Population-based druginduced agranulocytosis Arch Intern Med. 2005;165:869-874.

4. Moses A, Nelson J, Bagby GC. The influence of human immunodeficiency virus-1 on hematopoyesis. Blood 1998;91:14791495.

5. Góngora-Biachi R, Castro-Sansores C. Complicaciones sistémicas de la infección por el VIH y el sida. En: Góngora-Biachi R, editor. VIH y Sida: un enfoque a 25 años de su emergencia. Mérida: Ediciones del Grupo de Estudios de VIH/Sida del Sureste, 2006:155-169.

6. Coyle TE. Hematologic complications of human immunodeficiency virus infection and the acquired immunodeficiency syndrome. Med Clin North Am 1997;81:449-70.

7. Moore RD, Keruly JC, Chaisson RE. Neutropenia and bacterial infection in acquired immunodeficiency syndrome. Arch Intern Med 1995;155:1965-1970.

8. Moore D, Benepal T, Portsmouth S, Gill J, Gazzard B. Etiology and natural history of neutropenia in HIV disease: a prospective study. Clin Infect Dis 2001;32:469-476.

9. Levine AM, Karim R, Mack W, Gravnink J, Anastos K, Young M, et al. Neutropenia in human inmunodeficiency infection. Arch Intern Med 2006;166:405-410.

10. Nielsen SD, Ersboll AK, Mathiesen L, Nielsen JO, Hansen JES. Highly active antiretroviral therapy normalizes the function of progenitor cells in HIV-infected patients. J Infect Dis 1998;178:12991305.

11. Kuritzkes D. Neutropenia, neutrophil dysfunction, and bacterial infection in patients with HIV disease: the role of granulocyte colonystimulating factor. Clin Infect Dis 2000;30:256-260.

12. Aprikyan AG, Liles WC, Dale DC. Emerging role of apoptosis in the pathogenesis of severe neutropenia. Curr Opin Hematol 2000;7:131132.

\title{
Lesión nodular de mama de crecimiento rápido
}

\section{(A Nodular and Fast Growing Breast Mass)}

\author{
Gerardo Sáenz-Batalla', Pilar Bogantes-Ledesma³, Ángel Lazo-Valladares²,Alejandra Zúñiga-Bastos ${ }^{3}$
}

\section{Resumen:}

La hiperplasia estromal seudoangiomatosa es un hallazgo histológico benigno, relativamente infrecuente, caracterizada por aumento de la densidad mamaria, proliferación de fibras colágeno y del estroma que forma pseudoespacios capilares vacíos anastomosados entre sí. La etiología no es clara, pero tiene una marcada influencia hormonal. Tanto clínica como radiológicamente puede

\footnotetext{
ı. Médico cirujano general, jefe del servicio de Cirugía Hospital San Vicente de Paul

2. Médico patólogo, asistente del Servicio de Patología del Hospital México

3. Médicos asistentes generales del Servicio de Cirugía

Abreviaturas: $F A$, fibroadenoma mamaria; $F Q B$, mastopatía fibroquística de la mama; GM, ginecomastía; PASH, hiperplasia estromal seudoangiomatosa. Correspondencia: gesaba@racsa.co.cr, pilibogantes@hotmail.com, lazoangel@yahoo.com, alezul@hotmail.com

ISSN 0001-6002/2008/50/3/177-179

Acta Médica Costarricense, (O2008

Colegio de Médicos y Cirujanos
}

semejar lesiones benignas y malignas. La histología es fundamental para hacer el diagnóstico definitivo. Se reporta el caso clínico de una mujer herediana de 40 años con una masa mamaria derecha, deformante, asimétrica, de crecimiento rápido, dolorosa y multirecidivante, que finalmente resolvió con una mastectomía subcutánea.

Descriptores: hiperplasia estromal seudoangiomatosa, tumor filoides mamario, mastopatía fibroquística de la mama, ginecomastía

\section{Abstract \\ Pseudoangiomatous stromal hyperplasia of the breast is a rare benign disease, which was described by Vuitch in 1986. The etiology is not clear, but an hormonal influence has been demonstrated. To confirm the diagnosis, a biopsy is required primarily to distinguish a malignant disease like low grade angyosarcoma, a fibroadenoma or a Philloides}


tumor; these entities are similar in their clinical and imaging features. We present herein the case of a 40 year old female that presented with a fast growing, painful, recurrent breast mass, initially treated as fibrocystic breast disease but the histopathology later demonstrated the lesion to be a pseudoangiomatous stromal hyperplasia, which is very infrequent. Finally she underwent a sucutaneuos mastectomy, and the diagnosis was again confirmed. An extensive review of current literature confirmed that mastectomy is better, especially in cases with diffuse and recurrent tumors.

Key words: Pseudoangiomatous stromal hyperplasia, ginecomastia, philloides tumor, benign fibroquistic breast changes

Recibido: 19 de diciembre de 2007

Aceptado: 28 de abril de 2008

Se trata de una mujer de 40 años de edad, vecina de San Pablo de Heredia, con historia de dos años de evolución de un nódulo mamario derecho, antecedentes heredofamiliares de cáncer de mama en tía y abuela, hipertensa, multípara, salpingectomizada a los 28 años, con el hallazgo clínico de una masa retroareolar, asimétrica, móvil, de $10 \mathrm{~cm}$ de diámetro, duro elástica, sin retracciones, sin secreciones por el pezón, sin adenopatías palpables, en la unión de los cuadrantes superiores, de crecimiento muy rápido que modificaba sus características en relación con el ciclo menstrual siendo más dolorosa, grande y tumefacta unos días antes del sangrado menstrual. Había presentado 10 años atrás una lesión semejante, que se le resecó ampliamente, al recidivar, fue referida para seguir control y manejo en Cirugía del Hospital San Vicente de Paúl. El 4 de agosto de 2006 la mamografía reportaba "importante asimetría de la densidad en la mama derecha que compromete el tejido retro areolar y central de la mama, de $10 \mathrm{~cm}$, sin evidencia de lesión focal ni engrosamiento de la piel, sin adenopatías axilares y sin retracciones del pezón". El ultrasonido complementario de mamas realizado posteriormente, reportaba "aumento de la densidad y masa palpable en la mama derecha, sólida, heterogénea con calcificaciones en su interior de 10 por 5 centímetros, se recomienda exeresis", nuevamente. Llevada a sala de operaciones el 16 de noviembre de 2006 con el diagnóstico presuntivo de cambios fibroquísticos de mama derecha, la descripción macroscópica fue de "placa de gran tamaño, que se extrae en su totalidad, de aproximadamente $10 \mathrm{~cm}$ de diámetro"; la biopsia número 06341, recibida el 17 de noviembre del 2006 en el Hospital México, reporta: como "tres fragmentos de tejido grisáceo, de consistencia elástica, que miden $7 \times 7 \times 5 \mathrm{~cm}$ y que al corte presentan áreas quísticas de contenido mucoide y de superficie blanquecina, lisa". La descripción microscópica: "lesión blanquecina compuesta de tejido fibroso, con áreas colagenizadas y áreas ligeramente hipercelulares; que engloba estructuras túbulo lobulillares y un patrón seudoangiomatoso, en las áreas más celulares se distinguen células mixoides benignas que componen la lesión”. En febrero de 2007 durante la revisión postoperatoria, el cirujano describió de nuevo una tumoración en mama derecha entre el eje de las 11 y 12 , con características semejantes a la anterior. El 13 de marzo de 2007 se le realiza una cuadrantectomía y la biopsia reporta "fibrosis estromal, ectasia ductal y PASH" El 23 de junio de 2007, 3 meses después, al ser valorada por el cirujano, encuentra una recidiva de la lesión, pero con cambios inflamatorios de la piel y dolor intenso. Llevada a sesión de cirugía, luego de amplia discusión, con consentimiento de la paciente se le realiza una mastectomía subcutánea derecha, como tratamiento definitivo.

Discusión del caso: Dentro de la patología mamaria, la hiperplasia estromal seudoangiomatosa PASH por sus siglas en inglés, es un hallazgo histológico benigno, relativamente poco común, descrita por primera vez en 1986 por Vuits MF y Rosen PP. ${ }^{1,2}$ La lesión puede manifestarse difusamente como hallazgo microscópico o como un nódulo único, sólido y móvil, generalmente circunscrito y unilateral, aunque se han reportado casos bilaterales. Modifica su tamaño con el relación al ciclo menstrual, lo que sugiere una clara dependencia hormonal del tumor. ${ }^{1}$

Nuestro particular interés en presentar este caso resulta de la poca frecuencia e inusual manifestación clínica de PASH como una masa sólida, nodular, de crecimiento muy rápido y multirecidivante. Inicialmente, esta patología fue descrita en 9 mujeres premenopáusicas, histológicamente caracterizada por proliferación del estroma mamario, que semeja lesiones pseudovasculares con canales interanastomosados complejos en el parénquima, sin densidad colágeno en el estroma. Los pseudoespacios usualmente dilatados y vacíos, de ahí el término de seudoangiomatoso; este patrón para algunos autores es el resultado de la separación de las fibras colágenas. ${ }^{1-3}$

Milanezi et al estudiaron la inmunohistoquímica de la hiperplasia estromal pseudoangiomatosa en varones con ginecomastía (GM), y confirmaron el origen mesenquimal de la células del estroma en espacios pseudovasculares. Todos positivos para vimentina del músculo liso y un $80 \%$ tuvieron inmunoreeactividad para $\mathrm{CD} 34 .^{3} \mathrm{La}$ fuerte positividad de las células del estroma, por CD34 y vimentina confirman el origen miofibroblástico de la hiperplasia estromal pseudoangiomatosa. ${ }^{3}$ Las células epiteliales ductales frecuentemente tienen receptores estrogénicos y receptores de progesterona. En 1995 Badve y Sloane encontraron una fuerte asociación entre $\mathrm{PASH}$, el estroma mamario y lo que inicialmente nombraron como fases intermedias en la GM masculina. ". 3

Nairuto Taira en 2005, encontró solo 109 casos bien documentados en la bibliografía mundial a ese año. ${ }^{4} \mathrm{PASH}$ se ha asociado con entidades benignas que incluyen cambios fibroquísticos proliferativos y no proliferativos del estroma mamario, fibroadenoma y GM, pero también con lesiones malignas en menor grado. ${ }^{5,6}$ 


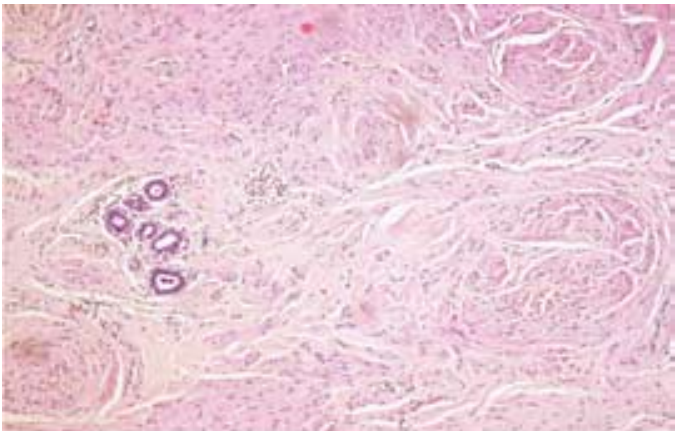

Figura 1. Fotografía a bajo aumento donde se observa la proliferación miofibroblástica que engloba estructuras ducto-lobulillares y que adopta patrón seudoangiomatoso

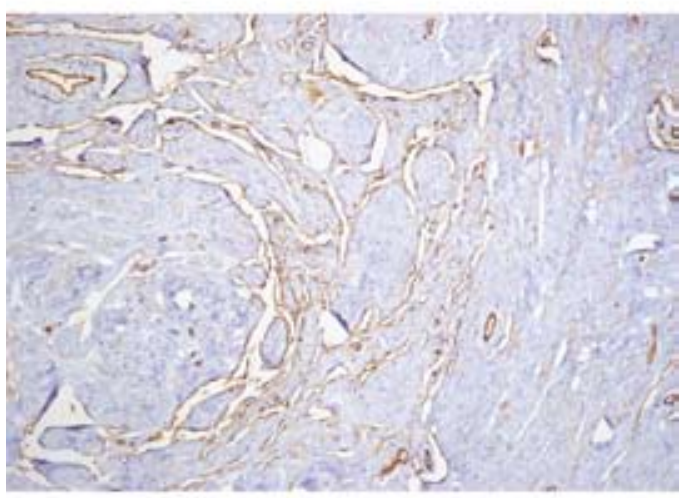

Figura 2. El marcador CD34 resalta los espacios claros, pero no marca la proliferación miofibroblástica.

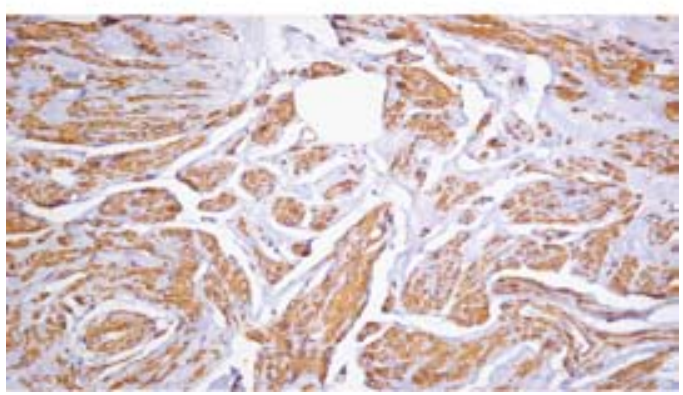

Figura 3. Las células miofibroblásticas que componen la lesión son fuertes y difusamente positivas para la actina de músculo liso.
En Bologna, Italia, se reportó el caso de tres pacientes con linfomas no Hodgkin`s de la mama, en un patrón muy semejante al que expresa PASH. El reporte histopatológico de nuestro caso es semejante, la inmunohistoquímica marcó con actina del músculo liso y fue positiva para CD34 también.

Científicos griegos han relacionado el marcador CD34, la actina del músculo liso y la GM, con la incidencia de cáncer de mama en varones, pero se sabe que puede ser un hallazgo de la fibrosis reactiva. ${ }^{6}$

Aunque PASH no maligniza en el largo plazo, un reporte de caso clínico de una angiomatosis lobular de la mama se relacionó con malignidad en un año, al presentarse un angiosarcoma. ${ }^{7}$

Las primeras descripciones ultrasonográficos y mamográficas, han sido muy inespecíficas e incluyen masas bien o parcialmente circunscritas, espiculadas, y aumento en las densidades del estroma mamario.

En 1999 Colegio Americano de Radiología reportó un caso semejante a este en una mujer con una masa palpable en el cuadrante superior externo de la mama derecha; la mamografía: una "lesión con bordes circunscritos en proyección mediolateral, sin calcificaciones", el ultrasonido complementario: "masa sólida hipo ecoica con espacios quísticos".

\section{Referencias}

1. Vuitch MF, Rosen PP, Erlandson RA. Pseudoangiomatous hyperplasia of mammary stroma. Hum Pathol 1986; 17: 185-91.

2. Arias MD, Pavcovich M, Jiménez I. Hiperplasia estromal seudoangiomatosa nodular de la mama. Sociedad Española de Anatomía Patológica, enero 2005.

3. Milanezi MF, Saggioro FP, Zanatti SG, Bazan R, Schmitt FC. Pseudoangiomatous hyperplasia of mammary estromal associated with gynecomastia. J Clin Pathol 1998; 51: 204-206.

4. NaIruto Taira, Shozo Ohsumi. Nodular Pseudoangiomatous stromal Hiperplasia of mammary stroma. Breast Canc 2005; 12:331-336.

5. Mercado C, MD, Shari A. Naidrich, MD. Pseudoangiomatous Stromal Hyperplasia of the Breast: Sonografic Features with Histopathologic Correlation. Breast J 2004; 427-432.

6. Rosen PP. Benign mesenchymal neoplasms. In: Rosen PP, ed- Rosen`s Breast Pathology. Philadelphia: Lippicott Raven, 1997: pp 659-664.

7. Bachleitner Hoffmann, T Schoppmann Sebastian F. A case of Tumor with Focal Transition into Low-grade Lymphangiosarcoma Breast Care 2006; 1: 391-393. 